\title{
Immediate corneal behavior after phacoemulsification, by means of spectral-domain optical coherence tomography
}

\section{Comportamiento corneal inmediato tras facoemulsificación, por medio de tomografía de coherencia óptica de dominio espectral}

\author{
Luis R. Alvarez-Fernández ${ }^{1 *}$, Oscar Baca-Lozada ${ }^{1}$, Héctor Pérez-Cano², Regina Velasco-Ramos \\ Elisa D. Alegría-Gómez ${ }^{1}$, and Oscar Fernández-Vizcaya ${ }^{1}$
}

${ }^{1}$ Department of Cornea and Refractive Surgery; ${ }^{2}$ Research Department. Fundación Hospital Nuestra Señora de la Luz Institución de Asistencia Privada, Mexico city, Mexico

\begin{abstract}
Objective: To describe the corneal changes in the first 24 hours after phacoemulsification, by means of spectral-domain optical coherence tomography (SD-OCT). Method: Prospective, observational, descriptive, cross-sectional and comparative study. Images taken by SD-OCT in eyes without a history of intraocular and corneal surgery were used to determine an average of thickness, density, reflectivity and normal characteristics of each corneal layer, in three age groups of 50-59 years, 60-69 years and 70-79 years. The characteristics of each cornea were described in relation to the effective phacoemulsification time (EPT). Results: We analyzed 180 eyes, finding a $p<0.0001$ for the total thickness in the 3 groups when comparing the corneas of the operated and non-operated eyes, where an increase of $13 \%$ was obtained between groups 1 and 2 , and an increase of $1 \%$ between groups 2 and 3 . The density compared by groups showed $p=0.0028, p=0.0011$ and $p<0.0001$, with a decrease of $-2.01 \%$ in group $1,-4.13 \%$ in group 2 and $-5.07 \%$ in group 3 . From an EPT $>8$ seconds, a decrease in the reflectivity of the stroma, Descemet's membrane and endothelium was found. Conclusions: The increase in corneal thickness is inversely proportional to corneal density; corneal reflectivity shows significant changes as EPT increases and phacoemulsification surgery produces multiple corneal changes observable by SD-OCT, despite the fact that they are sometimes not perceived by slit-lamp examination.
\end{abstract}

Keywords: Phacoemulsification. SD-OCT. Thickness. Density. Reflectivity. EPT.

\section{Resumen}

Objetivo: Describir los cambios corneales en las 24 horas posteriores a la facoemulsificación, por medio de tomografía de coherencia óptica de dominio espectral (SD-OCT). Método: Estudio prospectivo, observacional, descriptivo, transversal y comparativo. Se utilizaron imágenes tomadas por SD-OCT en ojos sin antecedentes de cirugía intraocular y corneal, para determinar un promedio de grosor, densidad, reflectividad y características normales de cada capa corneal, en tres grupos etarios de 50-59 años, 60-69 años y 70-79 años. Se describieron las características de cada córnea en relación con el tiempo efectivo de facoemulsificación (EPT). Resultados: Se analizaron 180 ojos, en donde el grosor etarios total en los tres grupos se encontró una $p<0.0001$ comparando las córneas de los ojos operados y no operados, en donde se obtuvo un aumento del 13\% entre el grupo 1 y 2 , y un aumento del 1\% entre el grupo 2 y 3 . La densidad comparada por grupos

Correspondence:

*Luis R. Alvarez-Fernández

Ezequiel Montes 135

Col. Tabacalera, Alcaldía Cuauhtémoc Date of reception: 08-02-2021

C.P. 06030 , Mexico City, Mexico

Date of reception: 08-02-2021

Available online: $05-11-2021$

E-mail: iraf_raise@ @otmail.com

DOI: 10.24875/RMOE.M21000193

Rev Mex Oftalmol (Eng). 2021;95(6):251-258

www.rmo.com.mx

2604-1731/@ 2021 Sociedad Mexicana de Oftalmología. Published by Permanyer. This is an open access article under the CC BY-NC-ND license (http://creativecommons.org/licenses/by-nc-nd/4.0/). 
mostró $p=0.0028, p=0.0011$ y $p<0.0001$, con una disminución de $-2.01 \%$ en el grupo $1,-4.13 \%$ en el grupo 2 y $-5.07 \%$ en el grupo 3. A partir de un EPT > 8 segundos se encontró una disminución en la reflectividad del estroma, la membrana de Descemet y el endotelio. Conclusiones: El aumento del grosor corneal es inversamente proporcional a la densidad corneal, la reflectividad corneal presenta cambios significativos conforme aumenta el EPT y la cirugía de facoemulsificación produce múltiples cambios corneales observables por SD-OCT, a pesar de que en la lámpara de hendidura en ocasiones no se perciban.

Palabras clave: Facoemulsificación. SD-OCT. Grosor. Densidad. Reflectividad. EPT.

\section{Introduction}

Evaluation of the cornea is an important part of the ophthalmic examination. There are several ways to do it, such as slit lamp visualization, ultrasound biomicroscopy or the use of spectral-domain optical coherence tomography (SD-OCT). The latter is a technique that does not use corneal contact and provides a high-resolution image that is used in various clinical situations ${ }^{1}$. SD-OCT is based on low coherence interferometry, measures the time delay and the intensity of backscattered infrared light using a diode that is super luminescent. The wavelength is approximately $1310 \mathrm{~nm}$; this measures the two beams of light by comparing the reflectivity in tissues, which is known as a reference mirror. These routes are sent to a computer, performing multiple longitudinal scans at a series of lateral locations to form a two-dimensional image ${ }^{2}$.

Corneal thickness measurement is useful in the diagnosis of certain corneal disorders, emphasizing its use in alterations that occur after phacoemulsification. As it is a high-resolution study, it can help to prematurely identify anatomical alterations, such as stromal edema ${ }^{3}$. Currently, clear corneal incisions are the most performed during phacoemulsification, since an important and useful property is their ability to close without suture, although this has increased the risk of endophthalmitis, so OCT has been used to evaluate how stromal hydration affects the architecture of these incisions in the immediate postoperative period ${ }^{4}$. Through SDOCT, the thicknesses of the different layers of a healthy cornea have been identified in its central portion: the epithelium measures approximately $50 \mu \mathrm{m}$, Bowman's membrane $12 \mu \mathrm{m}$, the stroma $500 \mu \mathrm{m}$, Descemet's membrane 4-10 $\mu \mathrm{m}$ and the endothelium $5 \mu \mathrm{m}^{5}$.

The transmission of light through the human cornea occurs due to the arrangement of collagen fibers, and the regulation of stromal dehydration is maintained in the endothelium by a series of molecular pumps, chemical modulators, and cell-binding properties ${ }^{6}$. Corneal abnormalities secondary to phacoemulsification can occur as a result of postoperative endothelial pump failure, due to mechanical or chemical injury, infection, or pre-existing endothelial compromise. There are associated risk factors that predispose to disorders and loss of endothelial cells, from preoperative factors, such as corneal endothelial dystrophies, glaucoma, uveitis, pseudoexfoliation syndrome and corneal trauma, to intraoperative factors, such as the surgeon's experience, the incision, the irrigation of solutions, surgical time, and vitreous and postoperative complications, such as vitreous in the anterior chamber, intraocular lens endothelial contact, wound dehiscence, anterior segment toxic syndrome, and Descemet's membrane detachment ${ }^{7,8}$.

Descemet's membrane detachment can be detected with the slit lamp if corneal edema is not severe, although the ideal test is $\mathrm{OCT}^{9,10}$. The resulting abnormalities in aquaporins, after the irrigation of solutions or the drugs used intraoperatively, can produce pseudophakic corneal edema. Phacoemulsification has been shown to damage corneal endothelial cells by generating free radicals, such as reduced glutathione, calcium, adenosine, sodium hyaluronate, superoxide dismutase, and ascorbic acid. Endothelial cells have both tight and discontinuous junctions that are calcium-dependent, so the use of irrigation solutions without calcium can reduce the barrier function that leads to corneal edema ${ }^{11}$.

Corneal edema is divided according to its temporality: immediate onset, which covers the first 24 hours and is characterized by endothelial trauma with functional cell failure, associated with excessive energy used during surgery, elevated intraocular pressure and Descemet 's membrane detachment, and late onset, where edema is manifested after a period of corneal clarity, characterized by progressive loss of endothelial cells, as aphakic and pseudophakic bullous keratopathy ${ }^{12}$. It is essential to manage intraocular pressure increases with ocular hypotensive drugs to prevent damage to endothelial cells; prostaglandin inhibitors, carbonic anhydrase inhibitors, and steroids should be used with caution in corneal edema ${ }^{13}$. Surgical options depend on the onset of corneal edema; if it is 
immediate, as in Descemet 's membrane detachment, gas or intracameral air is used, and if the onset is late, as in cases of irreversible endothelial damage, penetrating keratoplasty or posterior lamellar transplant are used $^{14}$. Descemet's membrane detachment after phacoemulsification has been classified into three types: simple when it is only located at the incision, symmetrical when it is located both at the incision and in the contralateral limbus, and complete when it also affects the central portion ${ }^{15}$.

Currently there are several anterior segment optical coherence tomographs; for example, the SD-OCT Heidelberg Spectralis ${ }^{\circledR}$, which is a low coherence interferometry system with high resolution images ${ }^{16,17}$ and that offers the option of adding positive and negative lenses to compensate for the patient's ametropia, in addition to have an excellent resolution in the measurement of corneal thickness and the exemplification of its characteristics, providing greater detail, so it can be considered as a "optical biopsy» ${ }^{18}$.

The objective of this study is to describe the corneal changes in the 24 hours after phacoemulsification, using SD-OCT.

\section{Methods}

Prospective, observational, descriptive, cross-sectional, and comparative study of corneal characteristics after phacoemulsification using SD-OCT, in 2019. Ninety patients aged 50 to 79 years were selected and divided into three groups: 50-59 years, $60-69$ years, and 70-79 years. The groups of operated eyes were assigned the numbers 1,2 and 3 , and the groups of non-operated eyes the letters $A, B$ and $C$. The patients were operated with a Stellaris PC Bausch \& Lomb $^{\circledR}$ equipment, documenting the effective time of phacoemulsification and that the contralateral eye has never had intraocular surgery neither corneal pathology that affects the central $3 \mathrm{~mm}$. SD-OCT was performed with the Heidelberg Spectralis ${ }^{\circledR}$ system in both eyes with an $8.3 \mathrm{~mm}$ zoom, obtaining an image with a quality $>20$ and $<35$, a single measurement in the immediate postoperative period in the course of the first 24 hours (90 eyes operated) and a single measurement in the contralateral eyes (90 healthy eyes). Thickness, density, reflectivity, and characteristics were divided and analyzed by age group, and we obtained the value of the correlation coefficient with the effective phacoemulsification time.

The density of the corneal layers was obtained by means of the Image $\mathrm{J}$ program of the National Institutes of Health, calibrating the image at $200 \mu \mathrm{m}$, which is the standardized value, measuring the density in grayscale of 256 8-bit pixels. The data obtained were captured into a Microsoft Excel spreadsheet with the patient identification card. The characteristics of the SD-OCT images of the corneal layers, thickness, reflectivity, and density, both in the operated and non-operated eyes, were analyzed in the central $3 \mathrm{~mm}$ outside the artifact.

Results were shown in graphs obtained by comparing the observed characteristics by age group. For the statistical analysis, the results were captured into the GraphPad Prism V5.0 program, the Kolmogórov-Smirnov test was performed, and when non-parametric results were obtained, the Mann-Whitney $U$ test was performed. Spearman's rho test was used for the correlation of EPT with density and thickness. A p-value of less than 0.05 was considered statistically significant.

\section{Results}

A statistically significant $p$ was found in the three age groups for corneal thickness ( $p<0.0001$ ) (Table 1), by comparing groups 1, 2 and 3 with groups A, B and C. It can be observed that the increase in total thickness depends on the increase in stromal thickness with a test ratio of 0.5963 ( $p<0.0001$ ) (Fig. 1). However, it was also observed that the difference in corneal thickness of the operated patients between group 1 and group 2 was $13 \%$, but the difference between groups 2 and 3 was $<1 \%$, indicating that age is a protective factor in group 1, compared to groups 2 and 3 ( $p<0.0001)$ (Fig. 2).

For corneal density, statistical significance was also found in the three age groups: groups 1 and $A$ $(p=0.0028)$, groups 2 and $B(p=0.0011)$, and groups 3 and $C(p<0.0001)$; by comparing the age groups of the operated eyes with the control eyes (Table 2). It can be observed that total density decreases at the expense of stromal, Descemet's membrane and endothelium density. There was a significant proportional decrease in corneal density of $3.33(-2.01 \%)$ in group 1 , of 6.8 $(-4.13 \%)$ in group 2 and of $8.55(-5.07 \%)$ in group 3; unlike corneal thickness, age did not play a protective factor here (Fig. 3).

Corneal reflectivity was similar in operated eyes and in control eyes in the three superficial layers of the cornea, but the Descemet's membrane and the endothelium of the control groups were hyperreflective. Compared with the corneas of the operated eyes, we observed hyperreflectic and hyporeflectic layers, and in 
Table 1. Corneal thickness. Groups 1, 2 and 3 correspond to phacoemulsification operated eyes and groups $A, B$ and $C$ correspond to non-operated contralateral eyes. The average value of thicknesses in microns is presented, and the values in parentheses correspond to the maximum and minimum

\begin{tabular}{|c|c|c|c|c|c|c|}
\hline & \multicolumn{2}{|c|}{$50-59$ years $(n=60)$} & \multicolumn{2}{|c|}{$60-69$ years $(n=60)$} & \multicolumn{2}{|c|}{$70-79$ years $(n=60)$} \\
\hline Groups & $1(n=30)$ & $A(n=30)$ & $2(n=30)$ & $B(n=30)$ & $3(n=30)$ & $C(n=30)$ \\
\hline Epithelium ( $\mu \mathrm{m})$ & (45-66) 52.40 & $\begin{array}{c}(43-59) \\
50.60\end{array}$ & $(43-80) 57.46$ & $(45-61) 52.86$ & (14-81) 55.76 & $(42-57) 50.93$ \\
\hline Bowman $(\mu \mathrm{m})$ & (9-19) 14.07 & (9-19) 15.37 & $(9-21) 14.7$ & (13-19) 15.23 & (8-18) 13.63 & (11-18) 15.13 \\
\hline Stroma $(\mu \mathrm{m})$ & (465-801) 589.76 & (415-493) 444.43 & (489-1024) 675.3 & $(413-530) 457.4$ & (468-979) 673.96 & $(411-515) 462.6$ \\
\hline $\begin{array}{l}\text { Descemet/ } \\
\text { endothelium }(\mu \mathrm{m})\end{array}$ & (12-19) 15.16 & $\begin{array}{c}(11-22) \\
15.93\end{array}$ & $(11-33) 16.46$ & $\begin{array}{c}(13-19) \\
16.00\end{array}$ & $(11-28) 15.63$ & $\begin{array}{c}(11-19) \\
15.4\end{array}$ \\
\hline \multirow[t]{2}{*}{ Total $(\mu \mathrm{m})$} & $(550-882) 671.46$ & $(498-571) 526.33$ & (569-1141) 763.93 & (496-617) 541.16 & (545-1076) 758 & (491-598) 544.33 \\
\hline & \multicolumn{2}{|c|}{$p<0.0001$} & \multicolumn{2}{|c|}{$p<0.0001$} & \multicolumn{2}{|c|}{$\mathrm{p}<0.0001$} \\
\hline
\end{tabular}

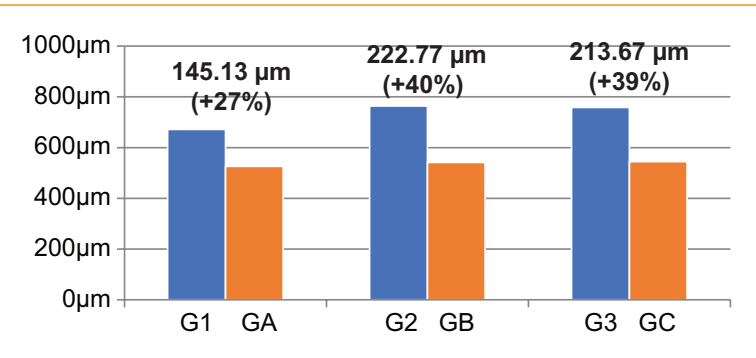

Figure 1. Corneal thickness. Groups 1, 2 and 3 correspond to the eyes operated on for phacoemulsification. Groups A, B and C correspond to the non-operated contralateral eyes. The increase in corneal thickness is compared between operated and non-operated eyes.

a minimum percentage (6.66\%) layers with hyperreflective characteristics in some segments of Descemet's membrane and the endothelium when an EPT $>8$ seconds was exceeded (Table 3).

The main characteristics observed in the operated corneas were stromal edema in $100 \%$, Descemet's membrane and endothelium hyperreflectivity in 64\% (Fig. 4), Descemet's membrane folds in $47 \%$, and Descemet's membrane detachment in 5.55\% (Fig. 5 and Table 4).

In the correlation tests, it was observed that the increase in stromal thickness is directly proportional to the increase in EPT (0.5963; $p<0.0001)$; however, stromal density is inversely proportional $(-0.1908$; $p=0.0359)$ and the normal density of Descemet's membrane and endothelium is $64 \%$ (Fig. 4), folds in

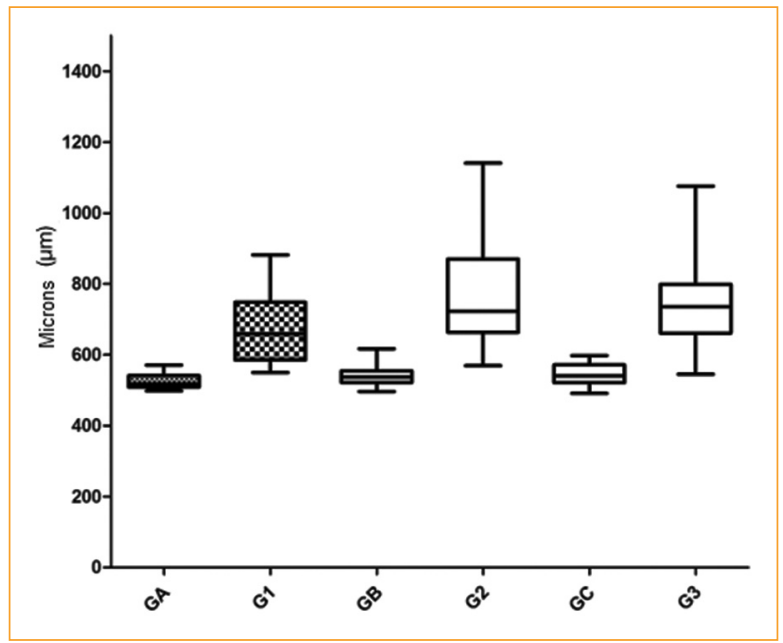

Figure 2. Corneal thickness. Groups 1, 2 and 3 correspond to the eyes operated on for phacoemulsification. Groups A, B and C correspond to the non-operated contralateral eyes. The increase in corneal thickness is compared between operated and non-operated eyes. There is a significant change between the 50-year-old group and the 60 - and 70 -yearold groups.

Descemet's membrane in $47 \%$, and Descemet's membrane detachment in 5.55\% (Fig. 5 and Table 4).

In the correlation tests, it was found that the increase in stromal thickness is directly proportional to the increase in EPT (0.5963; $p<0.0001)$; however, the stromal density is inversely proportional $(-0.1908 ; p=0.0359)$ and the normal density of Descemet's membrane and endothelium is inversely proportional when it exceeds 8 seconds of EPT $(-0.5957 ; p<0.0001)$ (Figs. 6 and 7). 
Table 2. Corneal density. Groups 1, 2 and 3 correspond to phacoemulsification operated eyes and groups A, B and C correspond to non-operated contralateral eyes. The average value of density in gray scale 2568 -bit pixels $\left(\mathrm{G} 2^{8} \mathrm{~b}\right)$ is presented, and the values that appear in parentheses correspond to the maximum and minimum

\begin{tabular}{|c|c|c|c|c|c|c|}
\hline \multirow[b]{2}{*}{ Groups } & \multicolumn{2}{|c|}{$50-59$ years $(n=60)$} & \multicolumn{2}{|c|}{$60-69$ years $(n=60)$} & \multicolumn{2}{|c|}{$70-79$ years $(n=60)$} \\
\hline & $1(\mathrm{n}=30)$ & $A(n=30)$ & $2(\mathrm{n}=30)$ & $B(n=30)$ & $3(n=30)$ & $C(n=30)$ \\
\hline $\begin{array}{l}\text { Epithelium } \\
\left(\mathrm{G} 2^{8} \mathrm{~b}\right)\end{array}$ & (96- 255) 198.28 & $(78-255) 181.16$ & (109-255) 212.35 & $(91-255) 182.35$ & (101-255) 207.03 & (100-255) 184.4 \\
\hline $\begin{array}{l}\text { Bowman } \\
\left.\text { (G2 }{ }^{8} \mathrm{~b}\right)\end{array}$ & (98- 229) 169.83 & (101-221) 157.3 & $(90-228) 180.46$ & (125-241) 168.95 & (133-240 191.45 & (127-228) 179.11 \\
\hline $\begin{array}{l}\text { Stroma } \\
\left(\mathrm{G} 2^{8} \mathrm{~b}\right)\end{array}$ & $(40-252) 148.16$ & $(68-251) 162.61$ & $(20-253) 143.15$ & $(68-251) 162.43$ & $(38-243) 138.96$ & (89-240) 166.73 \\
\hline $\begin{array}{l}\text { Descemet/ } \\
\text { Endothelium } \\
\text { (G28) }\end{array}$ & (22-247) 109.2 & (34-245) 137.98 & $(25-231) 94.91$ & (41-244) 143.41 & (30-208) 97.8 & (53-228) 141.48 \\
\hline \multirow[t]{2}{*}{$\begin{array}{l}\text { Total } \\
\text { (G28 b) }\end{array}$} & $\begin{array}{c}(140.12-196.12) \\
156.37\end{array}$ & $\begin{array}{c}(144.5-172.5) \\
159.7\end{array}$ & $\begin{array}{c}(140.75-178.62) \\
157.61\end{array}$ & $\begin{array}{c}(148.87-177.5) \\
164.41\end{array}$ & $\begin{array}{c}(142.12-172.12) \\
160.05\end{array}$ & $\begin{array}{c}(160.12-176.75) \\
168.6\end{array}$ \\
\hline & \multicolumn{2}{|c|}{$p=0.0028$} & \multicolumn{2}{|c|}{$p=0.0011$} & \multicolumn{2}{|c|}{$\mathrm{p}<0.0001$} \\
\hline
\end{tabular}

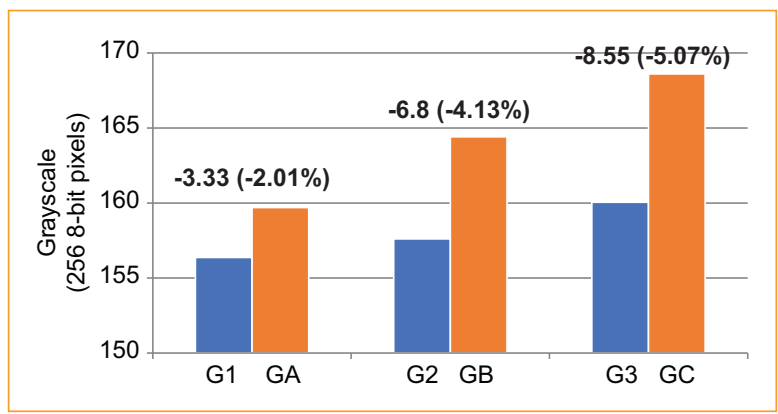

Figure 3. Corneal density. Groups 1, 2 and 3 correspond to the eyes operated on for phacoemulsification.

Groups $A, B$ and $C$ correspond to the non-operated contralateral eyes. The decrease in corneal density between operated and non-operated eyes is compared, 2568 -bit pixels $\left(G 2^{8} \mathrm{~b}\right)$ are represented in gray scale; the values that appear in parentheses correspond to the decrease in percentage.

\section{Discussion}

The use of ultrasound during cataract surgery modifies corneal architecture proportionally, since the more seconds of effective phacoemulsification time used, the more significant the anatomical changes will be. Sharma et al. ${ }^{9}$ found that there is corneal edema in all patients undergoing phacoemulsification regardless of the seconds used. In this study, edema was similar in all the corneas of the operated eyes, but it was also observed that this edema was not similar in all age groups, as well as the corneal density after 8 seconds of EPT.
During the corneal analysis using the SD-OCT images in the non-operated eyes, it was observed that the maximum reflectivity is observed in the epithelium and the minimum in the stroma, because the stroma is the layer of the cornea that is more hydrated. In eyes operated with phacoemulsification, endothelial reflectivity decreases to a minimum as stromal density decreases, observing that operated eyes of the 50-year-old group showed the highest endothelial reflectivity, because the younger the age, the higher the endothelial cell density; however, there was practically no difference between the 60- and 70-year-old groups.

Descemet's membrane detachment after phacoemulsification has been classified into three types: simple when it is only located at the incision, symmetrical when it is located both at the incision and in the contralateral limbus, and complete when it also affects the central portion. In the present study, five cases of Descemet's membrane detachment were identified: one in the 50-year-old group, one in the 60-year-old group, and three in the 70-year-old group. Age plays an important role, since Descemet's membrane is more likely to shed more easily during phacoemulsification in older patients.

There are not many studies that have used SD-OCT to describe corneal characteristics after cataract surgery, since most of the time it is taken for granted that anatomical changes will resolve with the correct use of the prescribed drugs in the postoperative period. However, we suggest that, in addition to slit lamp 
Table 3. Corneal reflectivity. Groups 1, 2 and 3 correspond to phacoemulsification operated eyes and groups $A$, B and $\mathrm{C}$ correspond to non-operated contralateral eyes. The results are represented as hyperreflectic and hyporeflectic depending on the reflectivity observed per layer in the spectral-domain optical coherence tomography images. The number of eyes is presented according to the reflectivity observed in each corneal layer, and the values in parentheses correspond to the percentage for each group

\begin{tabular}{|c|c|c|c|c|c|c|}
\hline \multirow[b]{2}{*}{ Groups } & \multicolumn{2}{|c|}{$50-59$ years $(n=60)$} & \multicolumn{2}{|c|}{$60-69$ years $(n=60)$} & \multicolumn{2}{|c|}{$70-79$ years $(n=60)$} \\
\hline & $1(n=30)$ & $A(n=30)$ & $2(n=30)$ & $B(n=30)$ & $3(n=30)$ & $C(n=30)$ \\
\hline Epithelium & \multicolumn{6}{|c|}{ Hyperreflective $180(100 \%)$} \\
\hline Bowman & \multicolumn{6}{|c|}{ Hyperreflective $180(100 \%)$} \\
\hline Stroma & \multicolumn{6}{|c|}{ Hyperreflective $180(100 \%)$} \\
\hline $\begin{array}{l}\text { Descemet/endothelium G } \\
\text { A, B y C } \\
(n=90)\end{array}$ & \multicolumn{6}{|c|}{ Hyperreflective $90(100 \%)$} \\
\hline $\begin{array}{l}\text { Descemet/endothelium G } 1 \\
(\mathrm{n}=30)\end{array}$ & Hyperre & e $18(60 \%)$ & Hyperrefl & $\begin{array}{l}\text { yperreflective } \\
\%)\end{array}$ & \multicolumn{2}{|c|}{$\begin{array}{l}\text { Hyperreflective } \\
6(20 \%)\end{array}$} \\
\hline $\begin{array}{l}\text { Descemet/endothelium G } 2 \\
(\mathrm{n}=30)\end{array}$ & Hyperrefl & $17(56.66 \%)$ & Hyperrefl & $\begin{array}{l}\text { yperreflective } \\
6 \%)\end{array}$ & \multicolumn{2}{|c|}{$\begin{array}{l}\text { Hyperreflective } \\
11(33.66 \%)\end{array}$} \\
\hline $\begin{array}{l}\text { Descemet/endothelium G } 3 \\
(\mathrm{n}=30)\end{array}$ & \multicolumn{2}{|c|}{ Hyperreflective 12 (40\%) } & Hyperrefl & $\begin{array}{l}\text { yperreflective } \\
6 \%)\end{array}$ & \multicolumn{2}{|c|}{$\begin{array}{c}\text { Hyperreflective } \\
16(53.33 \%)\end{array}$} \\
\hline
\end{tabular}

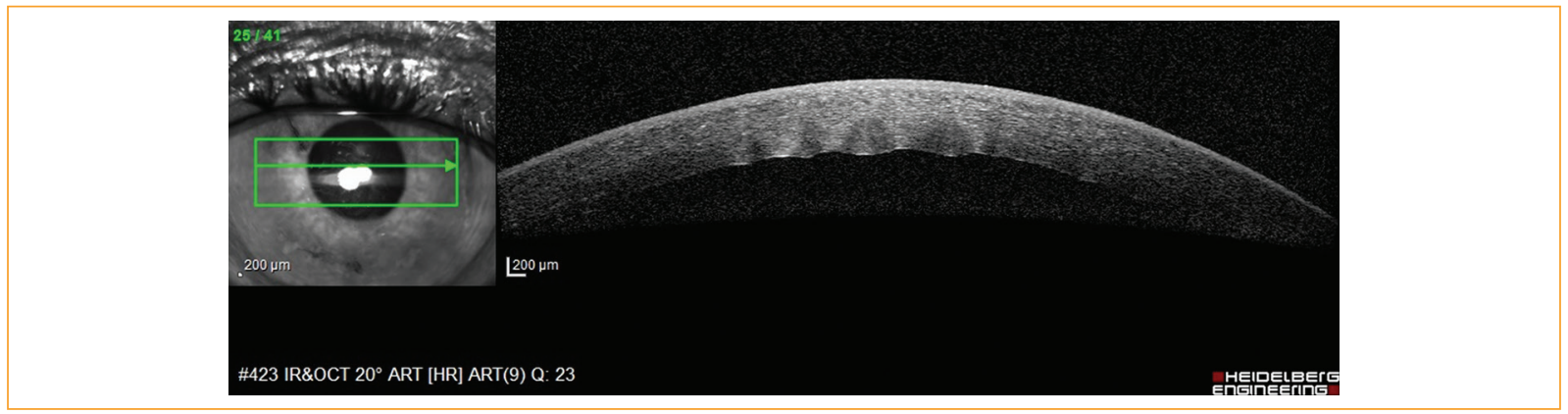

Figure 4. Descemet's membrane folds. Descemet's membrane folds were observed by SD-OCT in $47 \%$ of patients who underwent phacoemulsification.

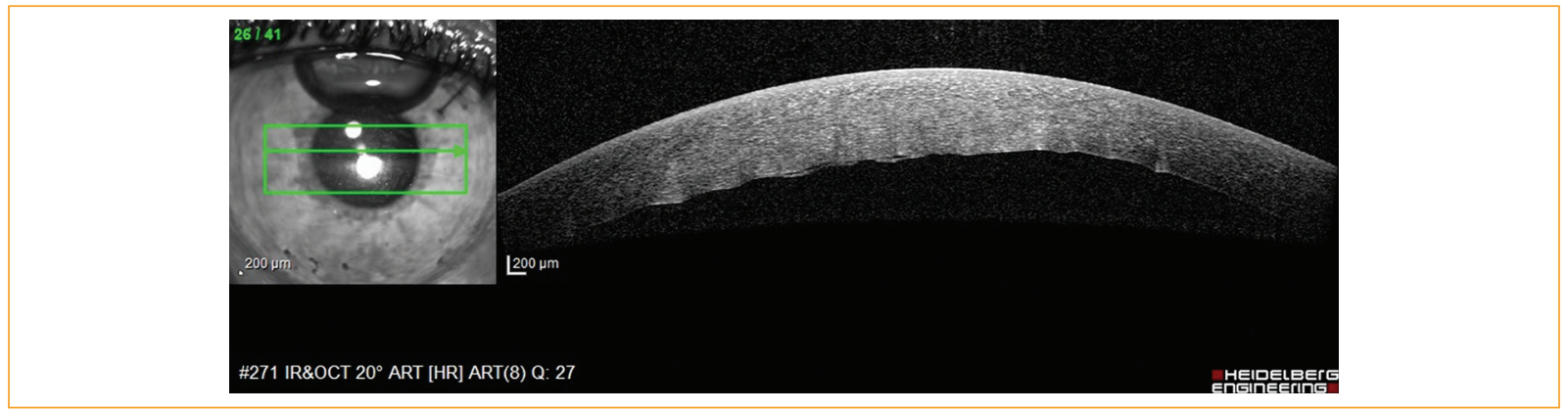

Figure 5. Stromal edema. Stromal edema was observed by SD-OCT in $100 \%$ of the patients who underwent phacoemulsification. 
Table 4. Corneal characteristics after phacoemulsification. Groups 1, 2 and 3 correspond to the eyes operated on for phacoemulsification. There was stromal edema in $100 \%$ of the cases, endothelial hyperreflectivity decreases with increasing age, Descemet's membrane folds did not show significant differences between age groups and there was Descemet's membrane detachment in three patients in group $3(10 \%)$, so it is suggested that age may be a determining factor for Descemet's membrane detachment

\begin{tabular}{|c|c|c|c|}
\hline & Group 1 (50-59 years) & Group 2 (60-69 years) & Group 3 (70-79 years) \\
\hline Stromal edema & $100 \%$ & $100 \%$ & $100 \%$ \\
\hline Endothelial hyperreflectivity & $80 \%$ & $64 \%$ & $47 \%$ \\
\hline Descemet's membrane folds & $39 \%$ & $53 \%$ & $49 \%$ \\
\hline Desceme'ts membrane detachment & $3 \%$ & $3 \%$ & $10 \%$ \\
\hline
\end{tabular}

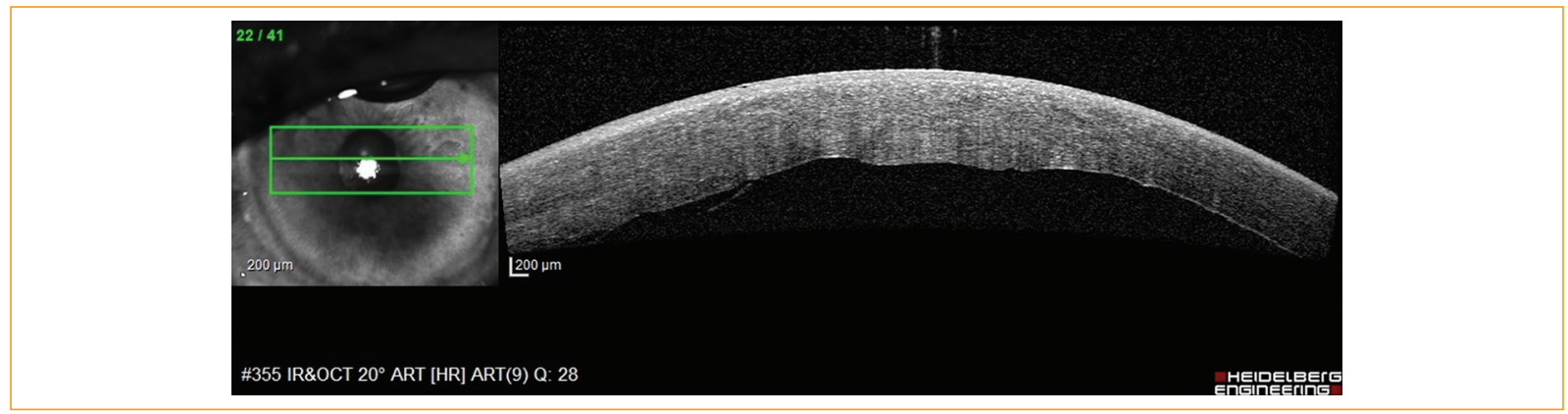

Figure 6. Descemet's membrane detachment. Descemet's membrane detachment was observed by SD-OCT in 5 patients who underwent phacoemulsification, and 3 patients correspond to the age group of $70-79$ years.
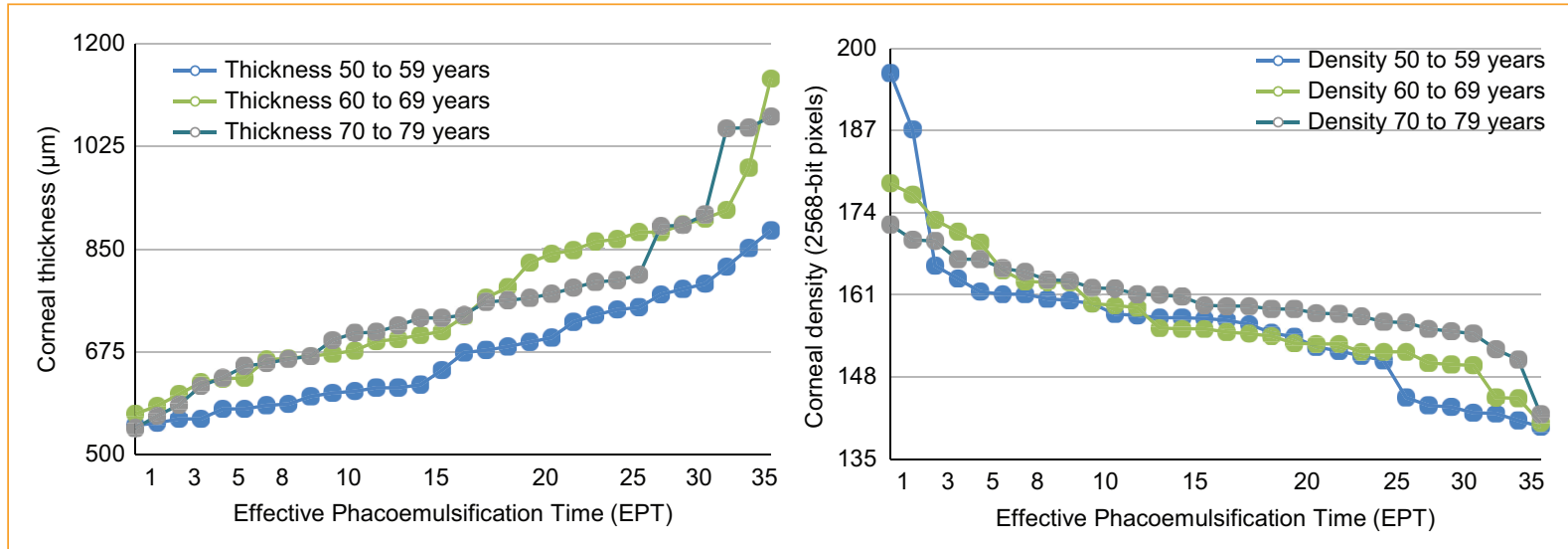

Figure 7. Comparison of corneal thickness and density. In the correlation tests, it was observed that the increase in corneal thickness is directly proportional to the increase in the effective phacoemulsification time (EPT) (0.5963; $p<0.0001)$; however, stromal density is inversely proportional to EPT $(-0.5957 ; p<0.0001)$.

biomicroscopy, it is useful to take advantage of the technological tools that we currently must establish a timely diagnosis and treatment of any complication, as well as to explain the visual prognosis to the patient.

\section{Conclusions}

Postoperative corneal changes are not innocuous, and it is essential to continue defining the characteristics in 
the different layers by objective methods, such as SDOCT, because some alterations require timely treatment. Increased corneal thickness is inversely proportional to density, although age can be a predictor depending on the use of ultrasound during phacoemulsification. Corneal reflectivity shows significant changes after an EPT $>8$ seconds, this being a factor to consider during cataract surgery. Finally, phacoemulsification produces multiple corneal changes observable by SD-OCT, despite the fact that they are sometimes not perceived by slitlamp examination.

\section{Funding}

The authors declare that the study did not receive any type of funding or financial contribution.

\section{Conflicts of interest}

The authors declare no conflicts of interest.

\section{Ethical disclosures}

Protection of human and animal subjects. The authors declare that no experiments were performed on humans or animals for this study.

Confidentiality of data. The authors declare that no patient data appear in this article.

Right to privacy and informed consent. The authors have obtained the written informed consent of the patients or subjects mentioned in the article. The corresponding author is in possession of this document.

\section{References}

1. Testoni PA. Optical coherence tomography. Scientific World J. 2007;7: 87-108.

2. Sakata LM, Wong TTL, Wong H-T, Kumar RS, Htoon HM, Aung HT, et al. Comparison of Visante and slit-lamp anterior segment optical coherence tomography in imaging the anterior chamber angle. Eye. 2010;224:578-87.

3. Xia Y, Liu X, Luo L, Zeng Y, Cai X, Zeng M, et al. Early changes in clear cornea incision after phacoemulsification: an anterior segment optical coherence tomography study. Acta Ophthalmol (Oxf). 2010;87:764-8.

4. Calladine D, Packard R. Clear corneal incision architecture in the immediate postoperative period evaluated using optical coherence tomography. J Cataract Refract Surg. 2007;33:1429-35.

5. Choi CY, Youm DJ, Kim MJ, Tchah H. Changes in central corneal thickness of preserved corneas over time measured using anterior segment optical coherence tomography. Cornea. 2009;28:536-40.

6. Yi DH, Dana MR. Corneal edema after cataract surgery: Incidence and etiology. Semin Ophthalmol. 2002;17:110-4.

7. Benai CA, Tsao JZ, Afshari NA. Descemet membrane detachment during cataract surgery: etiology and management. Curr Opin Ophthalmol. 2017;28:35-41.

8. Ozcelik ND, Eltutar K, Bilgin B. Toxic anterior segment syndrome after uncomplicated cataract surgery. Eur J Ophthalmol. 2010;20:106-14.

9. Sharma N, Gupta S, Maharana P, Shanmugam P, Nagpal R, Vajpayee RB, et al. Anterior segment optical coherence tomography-guided management algorithm for Descemet membrane detachment after intraocular surgery. Cornea. 2015;34:1170-4.

10. Jacob S, Agarwal A, Chaudhry P, Narasimhan S, Chaudhry VN. A new clinico-tomographic classification and management algorithm for Descemet's membrane detachment. Cont Lens Anterior Eye. 2015;38:327-33.

11. Rubowitz A, Assia El, Rosner M, Topaz M. Antioxidant protection against corneal damage by free radicals during phacoemulsification. Invest Ophthalmol Vis Sci. 2003;44:1866-70.

12. Narayanan R, Gaster RN, Kenney MC. Pseudophakic corneal edema: a review of mechanisms and treatments. Cornea. 2006;25:993-1004.

13. Bodh SA, Kumar V, Raina UK, Ghosh B, Thakar M. Inflammatory glaucoma. Oman J Ophthalmol. 2011;4:3-9.

14. Wang T. Analysis and treatment of detachment of corneal posterior elastic layer during cataract phacoemulsification. Int J Ophthalmol. 2014;8:1511-2.

15. Guo P, Pan Y, Zhang Y, Tighe S, Zhu Y, Li M, et al. Study on the classification of Descemet membrane detachment after cataract surgery with AS-OCT. Int J Med Sci. 2018;15:1092-7.

16. Li H, Leung CKS, Wong L, Cheung CYL, Pang CP, Weinreb RN, et al. Comparative study of central corneal thickness measurement with slitlamp optical coherence tomography and Visante optical coherence tomography. Ophthalmology. 2008;115:796-801.

17. Baikoff G, Lutun E, Ferraz C, Wei J. Static and dynamic analysis of the anterior segment with optical coherence tomography. J Cataract Refract Surg. 2004;30:1843-50.

18. Dada T, Sihota R, Gadia R, Aggarwal A, Mandal S, Gupta V. Comparison of anterior segment optical coherence tomography and ultrasound biomicroscopy for assessment of the anterior segment. J Cataract Refract Surg. 2007;33:837-40. 